\title{
Genetic variation in the oxytocin receptor (OXTR) gene is associated with Asperger Syndrome
}

\author{
Agnese Di Napoli ${ }^{1 *}$, Varun Warrier ${ }^{1}$, Simon Baron-Cohen ${ }^{1,2^{*}}$ and Bhismadev Chakrabarti ${ }^{1,3}$
}

\begin{abstract}
Background: Autism Spectrum Conditions (ASC) are a group of neurodevelopmental conditions characterized by impairments in communication and social interaction, alongside unusually repetitive behaviors and narrow interests. ASC are highly heritable and have complex patterns of inheritance where multiple genes are involved, alongside environmental and epigenetic factors. Asperger Syndrome (AS) is a subgroup of these conditions, where there is no history of language or cognitive delay. Animal models suggest a role for oxytocin (OXT) and oxytocin receptor (OXTR) genes in social-emotional behaviors, and several studies indicate that the oxytocin/oxytocin receptor system is altered in individuals with ASC. Previous studies have reported associations between genetic variations in the OXTR gene and ASC.
\end{abstract}

Methods: The present study tested for an association between nine single nucleotide polymorphisms (SNPS) in the OXTR gene and AS in 530 individuals of Caucasian origin, using SNP association test and haplotype analysis.

Results: There was a significant association between rs2268493 in OXTR and AS. Multiple haplotypes that include this SNP (rs2268493-rs2254298, rs2268490-rs2268493-rs2254298, rs2268493-rs2254298-rs53576, rs237885-rs22684 90-rs2268493-rs2254298, rs2268490-rs2268493-rs2254298-rs53576) were also associated with AS. rs2268493 has been previously associated with ASC and putatively alters several transcription factor-binding sites and regulates chromatin states, either directly or through other variants in linkage disequilibrium (LD).

Conclusions: This study reports a significant association of the sequence variant rs2268493 in the OXTR gene and associated haplotypes with AS.

Keywords: Autism Spectrum Conditions (ASC), Asperger Syndrome (AS), Oxytocin receptor (OXTR), Haplotype analysis

\section{Background}

Autism Spectrum Conditions (ASC) are a group of neurodevelopmental conditions characterized by difficulties in social interaction and communication, alongside unusually repetitive behaviors and narrow interests. Classic autism and Asperger Syndrome (AS) are two subgroups of ASC. They differ in that AS (unlike classic autism) has no history of language or cognitive delay [1]. The prevalence of ASC in the general population is around $1 \%$ [2], with a male:female sex ratio of $4: 1$ in classic autism [3], increasing to as high as 9:1 in AS [4]. ASC are

\footnotetext{
*Correspondence: agnesedinapoli@outlook.com; sb205@cam.ac.uk 'Autism Research Centre, Department of Psychiatry, University of Cambridge, Douglas House, 18B Trumpington Road, Cambridge CB2 8AH, UK ${ }^{2}$ Cambridgeshire and Peterborough NHS Foundation Trust, CLASS Clinic, Cambridge, Elizabeth House, Fulbourn Hospital, Cambridge CB21 5EF, UK Full list of author information is available at the end of the article
}

highly heritable, as indicated in three different twin studies [5-7]. Despite the high heritability, they are characterized by complex patterns of inheritance where multiple genes, epigenetic and environmental factors are involved. Many loci have been implicated in the predisposition to these conditions [8-10], but only a few of these loci have been well-replicated.

The oxytocin receptor (OXTR) gene encodes a member of the class I family of $\mathrm{G}$ protein-coupled receptors, which contains seven transmembrane domains. It occupies $17 \mathrm{~Kb}$ on chromosome $3 \mathrm{p} 25$ and includes four exons and three introns. It is mainly expressed in the mammalian reproductive system and brain (pre-limbic circuits, nucleus accumbens, thalamus and amygdala) [11-13]. Oxytocin receptor (OXTR) regulates the activity of oxytocin (OXT), a neuropeptide implicated in 
labor, uterine contraction and lactation. OXT is also involved in the establishment of maternal [14] and social [15] behaviors. The OXT and OXTR genes are good candidate genes for studying the genetic basis of ASC, because of their role in social-emotional behaviors [16-19]. Intranasal inhalation of OXT represents a potential treatment of ASC, improving social interaction [20] and emotion recognition [21].

A previous genetic study from our group identified a nominal association between the single nucleotide polymorphism (SNP) rs237880 in OXTR and autistic traits [22]. Several other studies reported an association between genetic variations in OXTR and ASC or related phenotypes. An association study in a Chinese population found that two SNPs (rs2254298 and rs53576) and haplotypes, including rs53576, are involved in the predisposition to ASC [23]. These findings were partially replicated in Japanese [24] and Caucasian [25] populations. Yrigollen et al. [26] identified an association between rs2268493 and affiliative behavior in ASC in a largely (93\%) Caucasian sample, while Campbell et al. [27] reported three SNPs (rs2268493, rs1042778, rs7632287) were nominally associated with ASC and related phenotypes. Another study conducted in a mixed-ethnicity population (84\% Caucasian, 4.9\% African-Canadian, 11.1\% 'other') found that a genetic variation (rs237885) and one haplotype (rs237885-2368493) in OXTR were associated with callous-unemotional traits, which are related to reduced empathy [28]. Two other studies reported an association between genetic variations in OXTR and autism-related phenotypes: empathy [29] and mindreading [30]. Finally epigenetic studies show that different methylation patterns in $O X T R$ are involved in the predisposition to classic autism [31] and variability of social perception [32].

In the current study we tested for a possible association of nine SNPs in OXTR with AS, performing a case-control study in a Caucasian population sample. We hypothesized that the SNPs in OXTR, alone or in combination, would be associated with AS. We did not have a specific hypothesis about any particular SNP, and hence mapped the gene using multiple SNPs. This approach is useful in testing the role of a candidate gene (rather than a specific SNP), since it allows a test of genetic association directly and by proxy [33].

\section{Methods}

\section{Ethical approval}

The current study was approved by both the Cambridge Psychology Research Ethics Committee and the NHS Research Ethics Committee (United Kingdom). The research was consistent with the Declaration of Helsinki. All participants gave informed consent to take part in the study.

\section{Participants}

All participants reported that they were of Caucasian origin for at least three generations (four Caucasian grandparents) and lived in northern Europe. They were recruited through the online database of Autism Research Centre in the University of Cambridge.

They were asked to complete the Autism Spectrum Quotient (AQ) online. The AQ is a measure of autistic traits and was used as a screen for cases and controls. Autistic traits are distributed continuously across the general population, where individuals with ASC represent one end of this continuum [34]. The AQ has high heritability in the general population [35] and individuals with AS have a mean AQ of $35.8 \pm 6.5$, while the mean $\mathrm{AQ}$ in the general population is $16.4 \pm 6.3$. An AQ score of $32+$ is a useful cut-off for ASC but is not diagnostic [36]. A total of 530 participants were selected: 118 cases (74 males and 44 females) and 412 controls (185 males and 227 females). This sample of participants does not overlap with the sample reported in the previous genetic study of AS carried out in our laboratory [22]. The mean age for cases was $40.5 \pm 15.3$ years, and for controls was $28.7 \pm 4.6$ years. Age difference between the two groups is not a confounding factor in this study, as age is not correlated with AQ or a diagnosis of AS. All cases had been previously diagnosed with AS by clinicians (psychiatrists or clinical psychologists) in recognized clinics in the United Kingdom using the criteria of the Diagnostic and Statistical Manual of Mental Disorders, Fourth Edition, Text Revision (DSM-IV-TR) [1] or the International Statistical Classification of Diseases and Related Health Problems, Tenth Revision (ICD-10) [37]. Controls had no diagnosis of ASC or any other psychiatric condition and did not have first-degree relatives with an ASC diagnosis. The AQ was used to validate the AS diagnosis in cases (AQ score $>32$ ) and select controls (AQ score $\leq 24$ ) from the low end of the distribution of autistic traits to avoid any risk of confounding controls with individuals who might have high autistic traits or undiagnosed ASC. Cases had a mean AQ of $35.6 \pm 8.9$ (range: 7 to 50 , males mean: $35.1 \pm 8.7$, females mean: $36.6 \pm 8.8$ ) and controls had a mean $\mathrm{AQ}$ of $14.9 \pm 5.0$ (range: 2 to 23 , males mean: $16.0 \pm 4.4$, females mean: $13.9 \pm 5.1)$.

\section{Single nucleotide polymorphism selection}

We selected nine SNPs in OXTR with a minor allele frequency $(\mathrm{MAF})>0.05$, as indicated by the dbSNP database and the HapMap genome browser, release 27 (operated by the National Institutes of Health $[\mathrm{NIH}]$, Bethesda, Maryland, United States) in the CEU (Utah residents with northern and western European ancestry) population. We chose SNPs located on chromosome 3 from 8795543 bp to $8810896 \mathrm{bp}$, to provide maximal coverage of OXTR. Inter-SNP distance was less than $5 \mathrm{~Kb}$ (GRCH37.p10 
Primary Assembly, National Center for Biotechnology Information $[\mathrm{NCBI}])$. The SNPs selected were available on the TaqMan SNP Genotyping Assays (Applied Biosystems Inc., California, United States) and rs237900 was a tag SNP (HapMap genome browser, release 27). rs2301261 (chr3: 8810896) and rs237885 (chr3: 8795543) are the most upstream and downstream SNPs on the gene, respectively (Table 1). Buccal swab kits were sent and returned by post and DNA was anonymized and extracted following a previously reported protocol [38]. SNP genotyping was performed using the TaqMan SNP genotyping assays as previously described [22]. None of the selected SNPs deviated from Hardy-Weinberg equilibrium, as tested using Plink v1.07 [39] at $\alpha=0.05$.

\section{Statistical analysis}

\section{Single nucleotide polymorphism association}

SNP association test was performed using Plink v1.07, to test for possible association between nine SNPs in OXTR and AS. We conducted the test under the null hypothesis of no association between each SNP and AS, using a significant level of $P<0.05$. Bonferroni correction was performed after controlling for linkage disequilibrium (LD) between the selected SNPs through the SNPSpD web interface [40]. The estimated average number of independent loci was seven and $\alpha$ was estimated to be equal to 0.0073 . Only $P$ values below or equal to the SNPSpD $\alpha$ threshold were considered significant for single SNP association analysis.

\section{Haplotype analysis}

Haplotype analysis in the case-control study was performed using Plink v1.07. We conducted omnibus two-, three- and four-loci haplotype analyses using logistic regression, under the null hypothesis of no association between haplotypes and AS. Permutation correction (50,000

Table 1 SNPs into the OXTR gene analyzed in the current study

\begin{tabular}{llll}
\hline SNP ID & $\begin{array}{l}\text { Chromosomal } \\
\text { position }(\mathbf{b p})\end{array}$ & $\begin{array}{l}\text { Derived/Ancestral } \\
\text { Allele }\end{array}$ & MAF \\
\hline rs237885 & 8795543 & T/G & $\mathrm{T}=0.438$ \\
rs2268490 & 8797085 & $\mathrm{~T} / \mathrm{C}$ & $\mathrm{T}=0.119$ \\
rs2268493 & 8800840 & $\mathrm{C} / \mathrm{T}$ & $\mathrm{C}=0.227$ \\
rs2254298 & 8802228 & $\mathrm{~A} / \mathrm{G}$ & $\mathrm{A}=0.070$ \\
rs53576 & 8804371 & $\mathrm{~A} / \mathrm{G}$ & $\mathrm{A}=0.413$ \\
rs237894 & 8806531 & $\mathrm{C} / \mathrm{G}$ & $\mathrm{C}=0.331$ \\
rs2268496 & 8808141 & $\mathrm{~T} / \mathrm{A}$ & $\mathrm{A}=0.222$ \\
rs237900 & 8808696 & $\mathrm{~A} / \mathrm{G}$ & $\mathrm{A}=0.406$ \\
rs2301261 & 8810896 & $\mathrm{~A} / \mathrm{G}$ & $\mathrm{A}=0.053$ \\
\hline
\end{tabular}

SNPs analyzed in this study are reported alongside their chromosomal position and MAF. Bp, base pair; MAF, minor allele frequency; SNP, single nucleotide polymorphism. permutations) was used to correct the $P$ values for family wise error rates (FWER). Permutation correction changes phenotype-genotype correlation but does not alter LD patterns between SNPs. Haplotypes with $P$ values equal or below the $\alpha$ threshold of 0.05 were considered significant. LD blocks in our sample and in the CEU population were analyzed using Haploview 4.2 [41]. Haplotype analysis in the CEU population was performed using data reported in the HapMap genome browser, release 27.

\section{Single nucleotide polymorphism annotation}

Functional annotation of significantly associated SNPs was performed using multiple tools. HaploReg [42] was used to predict the presence of regulatory motifs and conservation sites and to evaluate chromatin states. FSNP [43] provided an overall functional score for the genetic variations investigated. Previous genetic associations between the loci analyzed and ASC were detected through the Genetic Association Database [44]. Manual verification of the loci for functional roles was conducted using the University of California Santa Cruz (UCSC) genome browser [45]. Finally, SNPnexus provided information about structural variants and conservation sites in the loci analyzed [46].

\section{Results}

Single nucleotide polymorphism association

SNP rs2268493 was associated with AS (Table 2). This genetic variation localizes in intron 3 of $O X T R$ (see Figure 1) and showed a statistically significant association after Bonferroni correction for effective total number of SNPs (Table 2). None of the other SNPs were nominally associated with AS.

Table 2 Results of SNP association between nine genotyped SNPs in the OXTR gene and AS

\begin{tabular}{llllll}
\hline SNP ID & $\begin{array}{l}\text { Frequency } \\
\text { Minor Allele } \\
\text { (cases) }\end{array}$ & $\begin{array}{l}\text { Frequency } \\
\text { Minor Allele } \\
\text { (controls) }\end{array}$ & OR & $X^{\mathbf{2}}$ & $P$ value \\
\hline rs237885 & 0.4612 & 0.458 & 1.013 & 0.0074 & 0.9317 \\
rs2268490 & 0.1282 & 0.1382 & 0.9171 & 0.1535 & 0.6952 \\
rs2268493 & 0.2155 & 0.3074 & 0.619 & 7.442 & $\mathbf{0 . 0 0 6 3 7}$ \\
rs2254298 & 0.0862 & 0.1284 & 0.6404 & 3.062 & 0.0802 \\
rs53576 & 0.3559 & 0.3037 & 1.267 & 2.308 & 0.1287 \\
rs237894 & 0.3248 & 0.267 & 1.321 & 2.992 & 0.0837 \\
rs2268496 & 0.2179 & 0.2437 & 0.8648 & 0.6625 & 0.4157 \\
rs237900 & 0.3846 & 0.3897 & 0.9787 & 0.0199 & 0.8879 \\
rs2301261 & 0.0769 & 0.1078 & 0.6899 & 1.9 & 0.1681 \\
\hline significant & & & & &
\end{tabular}

Significant $P$ values after Bonferroni correction for total number of SNPs are written in bold and italicized. AS, Asperger Syndrome; OR, odds ratio; SNP, single nucleotide polymorphism. 


\section{Haplotype analysis}

One two-loci haplotype (rs2268493-rs2254298), two three-loci haplotypes (rs2268490-rs2268493-rs2254298, rs2268493-rs2254298-rs53576) and two four-loci haplotypes (rs237885-rs2268490-rs2268493-rs2254298, rs22 68490-rs2268493-rs2254298-rs53576) were associated with AS after permutation correction. All these haplotype combinations include rs2268493, which was associated with AS in the SNP association test (Table 3).

In our sample rs2268493 and rs2268490 form a $3 \mathrm{~Kb}$ LD block (Block 1; Figure 2). These two variations are part of two 4-loci haplotype combinations associated with AS (rs2268490-rs2268493-rs2254298-rs53576 and rs237885rs2268490-rs2268493-rs2254298) (Table 3). rs2268493 is included in an LD block in the CEU population (Block 20), alongside rs6790151, rs6777612, rs6790467 and rs6793234 (Figure 3).

\section{Discussion}

In the present study we conducted a case-control study in a Caucasian sample to test for genetic association between nine SNPs in the OXTR gene and AS. Our results indicate a significant association between the common genetic variant rs2268493 in OXTR and AS. These corroborate previously reported association between SNPs in OXTR and individuals with an ASC more broadly. The two most reported SNPs in OXTR that are associated with ASC are rs2254298 and rs53576 [23-25], while rs2268493 has been significantly [26] and nominally [27] associated with ASC in two different studies.
In the current study we find a genetic association of rs2268493 with AS, which remains significant after Bonferroni correction. Haplotype analysis reports significant association of five haplotypes in OXTR with AS (rs2268493-rs2254298, rs2268490-rs2268493-rs2254298, rs2268493-rs2254298-rs53576, rs237885-rs2268490-rs226 8493-rs2254298, rs2268490-rs2268493-rs2254298-rs535 76). rs2268493 is included in all of these haplotype combinations and it localizes, along with rs2268490, in an LD block associated with AS in our sample. In the CEU population, rs2268493 localizes in an LD block with other four SNPs (rs6790151, rs6777612, rs6790467 and rs6793234).

rs2268493 is included in intron 3 of OXTR (Figure 1) and it localizes $5930 \mathrm{bp}$ upstream of the intron 3-exon 4 splice junction. Functional annotation indicates that this genetic variation alters six different transcription factor-binding sites (F-SNP, HaploReg). Among them are SOX_3 and Pou3f3, which are involved in neural development $[47,48]$. Moreover, rs2268493 and haplotypes that include this variation have been reported to be associated with ASC in earlier reports [26,27]. $O X T R$ has four splice variants and three of them are protein-coding; one transcript includes four exons and three introns, another variant is composed of the first three exons (1, 2 and 3) and introns 1 and 2, and the other two variants include exon 1 , intron 1 and part of exon 2 (UCSC genome browser). Genetic variations that disrupt regulatory regions can affect gene expression in a time- and tissue-specific manner. Molecular studies are needed to understand this further. rs2268493

Table 3 Results of haplotype analysis in the AS case-control study

\begin{tabular}{lllll}
\hline Number of SNPs & Haplotype combination & Chromosomal position & $\boldsymbol{P}$ value & FWER corrected $\boldsymbol{P}$ value \\
\hline 2 & rs2268493-rs2254298 & $8800840-8802228$ & 0.00086 & 0.00468 \\
3 & rs2268490-rs2268493-rs2254298 & $8797085-8802228$ & 0.000365 & 0.0018 \\
3 & rs2268493-rs2254298-rs53576 & $8800840-8804371$ & 0.00208 & 0.01268 \\
4 & rs237885-rs2268490-rs2268493-rs2254298 & $8795543-8802228$ & 0.0012 & 0.00712 \\
4 & rs2268490- rs2268493-rs2254298-rs53576 & $8797085-8804371$ & 0.00132 & 0.0079 \\
\hline
\end{tabular}

Haplotypes with significant $P$ values after permutation correction are reported. AS, Asperger Syndrome; FWER, family-wise error rates; SNPs, single nucleotide polymorphisms. 


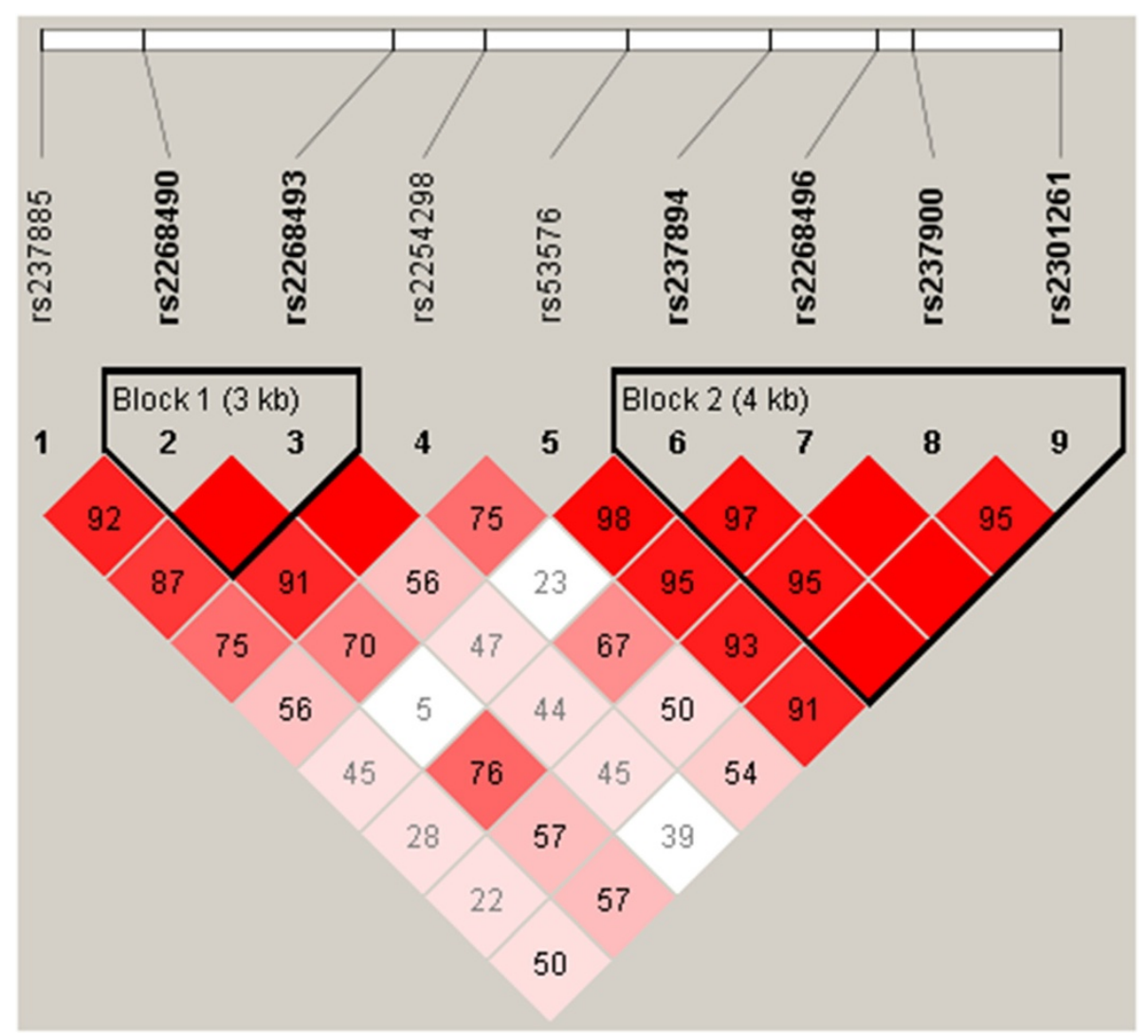

Figure 2 Linkage disequilibrium plot of the OXTR gene calculated in the sample studied. Numbers in the squares indicate $D^{\prime}$ values.

localizes in an LD block when calculated in the general population, where four other SNPs are included. Three SNPs (rs6777612, rs6790467 and rs6793234) alter regions that regulate the chromatin states in several neuronal cell lines (such as fetal brain and substantia nigra) (HaploReg).

This is the first study which reports a statistically significant association between one SNP (rs2268493) in
OXTR with AS in a Caucasian sample, as other studies have focused on the whole spectrum of ASC. A previous study from our laboratory analyzed the genetic association between candidate genes (including OXTR) and AS [22] in an independent sample, while the current study represents a more in-depth analysis of the involvement of OXTR in AS. Campbell et al. have previously

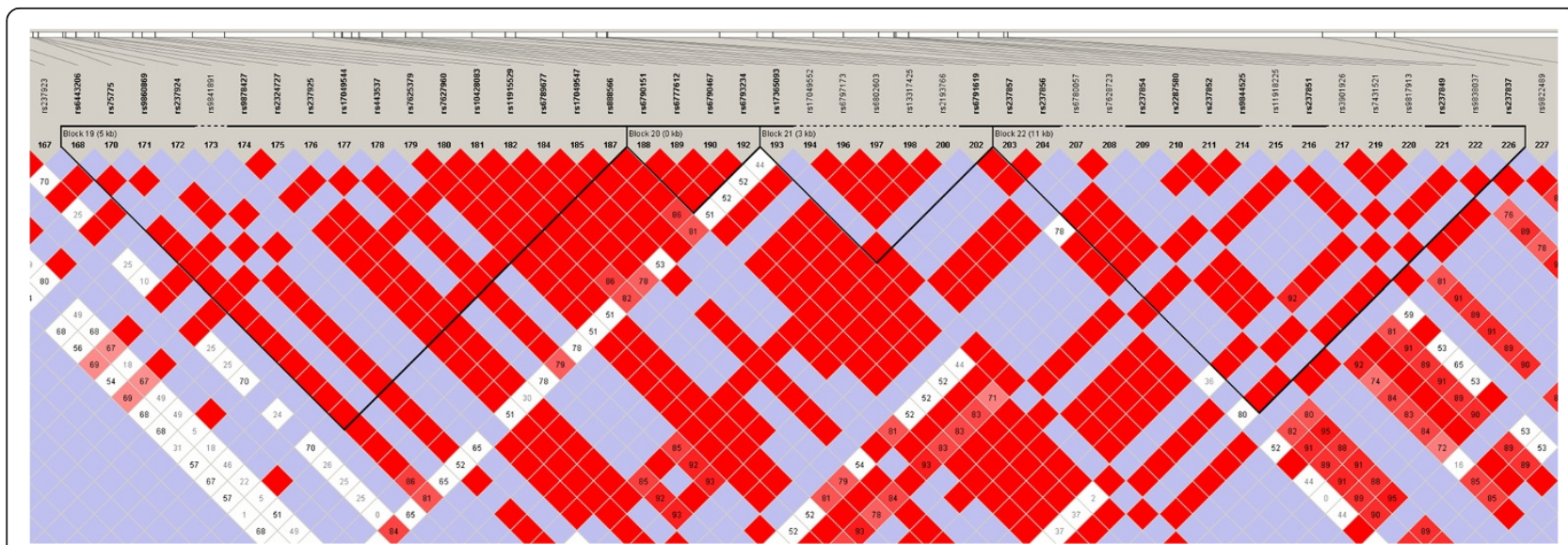

Figure 3 Linkage disequilibrium plot of the OXTR gene calculated in the CEU (Utah residents with northern and western European ancestry) population (detail). Numbers in the squares indicate D' values. 
reported a nominally significant association between this SNP and a narrow ASC diagnosis in family-based samples [27]. However, another study by Li et al. failed to identify any association between the same SNP and ASC in a Japanese population [24]. Such differences can arise due to differences between populations studied, as well as differences in criteria for diagnoses between AS and other subgroups of ASC. It is currently unclear if these differences can be explained by a different genetic architecture underlying these conditions. One way to test this hypothesis is by investigating common variants in candidate genes in AS specifically.

A limitation of this study is the moderate sample size and so further studies are necessary to confirm our findings. Multiple genes are involved in the predisposition for ASC, interacting with epigenetic and environmental factors. For this reason a single polymorphism or haplotype is unlikely to be the sole cause of these conditions. Testing this SNP for association with endophenotypes related to ASC will be an interesting next step.

\section{Conclusions}

In summary, we report a significant association between a common genetic variant in the OXTR gene (rs2268493) with AS. Five haplotypes that include this variant are also associated with AS. This provides further evidence suggesting a role of the oxytocinergic system in the aetiology of ASC, and shows that rs2268493 in OXTR is associated with AS, a high-functioning form of ASC.

\section{Abbreviations \\ AQ: Autism Spectrum Quotient; AS: Asperger Syndrome; ASC: Autism Spectrum Conditions; FWER: Family wise error rates; LD: Linkage disequilibrium; MAF: Minor allele frequency; OXT: Oxytocin; OXTR: Oxytocin receptor; SNP: Single nucleotide polymorphism.}

\section{Competing interests}

The authors declare that they have no competing interests.

\section{Authors' contributions}

ADN analyzed the data, under the guidance of $W$ and $B C$. BC and SBC designed the study and SBC obtained funding for the study. All authors contributed to the drafting of the manuscript. All authors read and approved the final manuscript.

\section{Authors' information}

ADN and WW are joint first authors; SBC and BC are joint senior authors.

\footnotetext{
Acknowledgments

This study was funded by project grants to SBC from Target Autism Genome, the Nancy Lurie Marks (NLM) Family Foundation, the Autism Research Trust, the Medical Research Council United Kingdom, the Wellcome Trust Sanger Centre, and the Max Planck Institute for Psycholinguistics. BC was funded by the Medical Research Council United Kingdom. WW was funded by the Nehru Trust for Cambridge University, St John's College Cambridge, and the Cambridge Commonwealth Trust, and this work was submitted in part fulfilment of the degree of MPhil at Cambridge University by $\mathrm{W}$. The study was undertaken in association with the National Institute of Health Research (NIHR) Collaborations for Leadership in Applied Health Research and Care (CLAHRC) East of England (EoE). We are thankful to Robert Plomin, Frank Dudbridge, Lindsey Kent and lan Craig for discussions, and to Laura Murphy, Jon Breidbord, Allen Chan, Sylvia Lakatosova, Sally
}

Wheelwright, Carrie Allison, Uma Mallya, Alex Politt, and the late Leena Peltonen for support at different stages of the project. Simon Fisher provided part funding for the project.

\section{Author details}

${ }^{1}$ Autism Research Centre, Department of Psychiatry, University of Cambridge, Douglas House, 18B Trumpington Road, Cambridge CB2 8AH, UK. ${ }^{2}$ Cambridgeshire and Peterborough NHS Foundation Trust, CLASS Clinic, Cambridge, Elizabeth House, Fulbourn Hospital, Cambridge CB21 5EF, UK. ${ }^{3}$ Centre for Integrative Neurosciences and Neurodynamics, School of Psychology and Clinical Language Sciences, University of Reading, Reading RG6 6AL, UK.

Received: 3 April 2014 Accepted: 27 August 2014

Published: 16 September 2014

\section{References}

1. American Psychiatric Association: DSM-IV Diagnostic and Statistical Manual of Mental Disorders. 4th edition. Washington, DC: American Psychiatric Association; 2000.

2. Baron-Cohen S, Scott FJ, Allison C, Williams JG, Bolton P, Matthews FE, Brayne C: Prevalence of autism-spectrum conditions: UK school-based population study. Br J Psychiatry 2009, 194:500-509.

3. Chakrabarti S, Fombonne E: Pervasive developmental disorders in preschool children. JAMA 2001, 285:3093-3099.

4. Gillberg C, Cederlund M, Lamberg K, Zeijlon L: Brief report: "The autism epidemic". The registered prevalence of autism in a Swedish urban area. J Autism Dev Disord 2006, 36:429-435.

5. Bailey A, Le Couteur A, Gottesman I, Bolton P, Simonoff E, Yuzda E, Rutter M: Autism as a strongly genetic disorder: evidence from a British twin study. Psychol Med 1995, 25:63-77.

6. Folstein S, Rutter M: Infantile autism: a genetic study of 21 twin pairs. J Child Psychol Psychiatry Allied Disciplines 1977, 18:297-321.

7. Steffenburg S, Gillberg C, Hellgren L, Andersson L, Gillberg IC, Jakobsson G, Bohman M: A twin study of autism in Denmark, Finland, Iceland, Norway and Sweden. J Child Psychol Psychiatry Allied Disciplines 1989, 30:405-416.

8. Folstein SE, Rosen-Sheidley B: Genetics of autism: complex aetiology for a heterogeneous disorder. Nat Rev 2001, 2:943-955.

9. Persico AM, Bourgeron T: Searching for ways out of the autism maze: genetic, epigenetic and environmental clues. Trends Neurosci 2006, 29:349-358.

10. Persico AM, Napolioni V: Autism genetics. Behav Brain Res 2013, 251:95-112.

11. Inoue T, Kimura T, Azuma C, Inazawas J, Takemura M, Kikuchi T, Kubota Y, Ogita K, Saji F: Structural organization of the human oxytocin receptor gene. J Biol Chem 1994, 269:32451-32456.

12. Kimura T, Tanizawa O, Mori K, Brownstein MJ, Okayama H: Structure and expression of a human oxytocin receptor. Nature 1992, 365:526-529.

13. Yamasue $\mathrm{H}$ : Function and structure in social brain regions can link oxytocin-receptor genes with autistic social behavior. Brain and Development 2013, 35:111-118.

14. Feldman R, Weller A, Zagoory-Sharon O, Levine A: Evidence for a neuroendocrinological foundation of human affiliation: plasma oxytocin levels across pregnancy and the postpartum period predict mother-infant bonding. Psychol Sci 2007, 18:965-970.

15. Ebstein RP, Israel S, Lerer E, Uzefovsky F, Shalev I, Gritsenko I, Riebold M, Salomon S, Yirmiya N: Arginine vasopressin and oxytocin modulate human social behavior. Ann NY Acad Sci 2009, 1167:87-102.

16. Kogan A, Saslow LR, Impett EA, Oveis C, Keltner D, Rodrigues Saturn S: Thinslicing study of the oxytocin receptor (OXTR) gene and the evaluation and expression of the prosocial disposition. Proc Natl Acad Sci U S A 2011, 108:19189-19192.

17. Sala M, Braida D, Lentini D, Busnelli M, Bulgheroni E, Capurro V, Finardi A Donzelli A, Pattini L, Rubino T, Parolaro D, Nishimori K, Parenti M, Chini B: Pharmacologic rescue of impaired cognitive flexibility, social deficits, increased aggression, and seizure susceptibility in oxytocin receptor null mice: a neurobehavioral model of autism. Biol Psychiatry 2011, 69:875-882.

18. Tops M, van ljzendoorn MH, Riem MM, Boksem MA, Bakermans-Kranenburg MJ: Oxytocin receptor gene associated with the efficiency of social auditory processing. Front Psychiatr 2011, 2:1-4. 
19. Takayanagi Y, Yoshida M, Bielsky IF, Ross HE, Kawamata M, Onaka T, Yanagisawa T, Kimura T, Matzuk MM, Young L, Nishimori K: Pervasive social deficits, but normal parturition, in oxytocin receptor-deficient mice. Proc Natl Acad Sci U S A 2005, 102:16096-16101.

20. Tachibana M, Kagitani-Shimono K, Mohri I, Yamamoto T, Sanefuji W, Nakamura A, Oishi M, Kimura T, Onaka T, Ozono K, Taniike M: Long-term administration of intranasal oxytocin is a safe and promising therapy for early adolescent boys with autism spectrum disorders. J Child Adolesc Psychopharmacol 2013, 23:123-127.

21. Guastella AJ, Einfeld SL, Gray KM, Rinehart NJ, Tonge BJ, Lambert TJ, Hickie IB: Intranasal oxytocin improves emotion recognition for youth with autism spectrum disorders. Biol Psychiatry 2010, 67:692-694.

22. Chakrabarti B, Dudbridge F, Kent L, Wheelwright S, Hill-Cawthorne G, Allison C, Banerjee-Basu S, Baron-Cohen S: Genes related to sex steroids, neural growth, and social-emotional behavior are associated with autistic traits, empathy, and Asperger Syndrome. Autism Res 2009, 2:157-177.

23. Wu S, Jia M, Ruan Y, Liu J, Guo Y, Shuang M, Gong X, Zhang Y, Yang X, Zhang D: Positive association of the oxytocin receptor gene (OXTR) with autism in the Chinese Han Population. Biol Psychiatry 2005, 58:74-77.

24. Liu X, Kawamura Y, Shimada T, Otowa T, Koishi S, Sugiyama T, Nishida H, Hashimoto O, Nakagami R, Tochigi M, Umekage T, Kano Y, Miyagawa T, Kato N, Tokunaga K, Sasaki T: Association of the oxytocin receptor (OXTR) gene polymorphisms with autism spectrum disorder (ASD) in the Japanese population. J Hum Genet 2010, 55:137-141.

25. Jacob S, Brune CW, Carter CS, Leventhal BL, Lord C, Cook EH Jr: Association of the oxytocin receptor gene (OXTR) in Caucasian children and adolescents with autism. Neurosci Lett 2007, 417:6-9.

26. Yrigollen C, Han SS, Kochetkova A, Babitz T, Chang JT, Volkmar FR, Leckman JF, Grigorenko EL: Genes controlling affiliative behavior as candidate genes for autism. Biol Psychiatry 2008, 63:911-916

27. Campbell DB, Datta D, Jones ST, Lee EB, Sutcliffe JS, Hammock EAD, Levitt $P$ : Association of oxytocin receptor (OXTR) gene variants with multiple phenotype domains of autism spectrum disorder. J Neurodevelop Disord 2011, 3:101-112.

28. Beitchman JH, Zai CC, Muir K, Berall L, Nowrouzi B, Choi E, Kennedy JL: Childhood aggression, callous-unemotional traits and oxytocin genes. Eur Child Adolesc Psychiatry 2012, 21:125-132.

29. Wu N, Li Z, Su Y: The association between oxytocin receptor gene polymorphism (OXTR) and trait empathy. J Affect Disord 2012, 138:468-472.

30. Lucht MJ, Barnow S, Sonnenfeld C, Ulrich I, Grabe HJ, Schroeder W, Völzke $\mathrm{H}$, Freyberger $\mathrm{HJ}$, John U, Herrmann FH, Kroemer H, Rosskopf D: Associations between the oxytocin receptor gene (OXTR) and "mindreading" in humans-an exploratory study. Nord J Psychiatry 2013, 67:15-21.

31. Gregory SG, Connelly JJ, Towers AJ, Johnson J, Biscocho D, Markunas CA Lintas C, Abramson RK, Wright HH, Ellis P, Langford CF, Worley G, Delong GR, Murphy SK, Cuccaro ML, Persico A, Pericak-Vance MA: Genomic and epigenetic evidence for oxytocin receptor deficiency in autism. BMC Medicine 2009, 7:62-74.

32. Jack A, Connelly JJ, Morris JP: DNA methylation of the oxytocin receptor gene predicts neural response to ambiguous social stimuli. Front Hum Neurosci 2012, 6:1-7.

33. Collins FS, Guyer MS, Chakravarti A: Variations on a theme: cataloging human DNA sequence variation. Science 1997, 278:1580-1581.

34. Robinson E, Munir K, Munafò MR, Hughes M, McCormick M, Koenen KC: Stability of autistic traits in the general population: further evidence for a continuum of impairment. J Am Acad Child Adolesc Psychiatry 2011, 50:376-384

35. Hoekstra RA, Bartels M, Verweij CJH, Boomsma DI: Heritability of autistic traits in the general population. Arch Pediatr Adolesc Med 2007, 161:372-377.

36. Baron-Cohen S, Wheelwright S, Skinner R, Martin J, Clubley E: The autismspectrum quotient (AQ): evidence from asperger syndrome/high-functioning autism, males and females, scientists and mathematicians. J Autism Dev Disord 2001, 31:5-17.

37. World Health Organization: The ICD-10 classification of mental and behavioural disorders: clinical descriptions and diagnostic guidelines. Geneva: World Health Organization; 1992.

38. Freeman B, Smith N, Curtis C, Huckett L, Mill J, Craig IW: DNA from buccal swabs recruited by mail: evaluation of storage effects on long-term stability and suitability for multiplex polymerase chain reaction genotyping. Behav Genet 2003, 33:67-72.

39. Purcell S, Neale B, Todd-Brown K, Thomas L, Ferreira MAR, Bender D, Maller J, Sklar P, De Bakker PIW, Daly MJ, Sham PC: PLINK: a tool set for wholegenome association and population-based linkage analyses. Am J Hum Genet 2007, 81:559-575. http://pngu.mgh.harvard.edu/ purcell/plink/.

40. Nyholt DR: A simple correction for multiple testing for SNPs in linkage disequilibrium with each other. Am J Hum Genet 2004, 74:765-769. http://gump.qimr.edu.au/general/daleN/SNPSpD/.

41. Barrett JC, Fry B, Maller J, Daly MJ: Haploview: analysis and visualization of LD and haplotype maps. Bioinformatics 2005, 21:263-265. http://www.broad.mit.edu/mpg/haploview.

42. Ward LD, Kellis M: HaploReg: a resource for exploring chromatin states, conservation, and regulatory motif alterations within sets of genetically linked variants. Nucleic Acids Res 2012, 40:D930-D934 http://www.broadinstitute.org/mammals/haploreg/haploreg.php.

43. Lee $\mathrm{PH}$, Shatkay $\mathrm{H}$ : An integrative scoring system for ranking SNPs by their potential deleterious effects. Bioinformatics 2009, 25:1048-1055. http://compbio.cs.queensu.ca/F-SNP/.

44. Becker KG, Barnes KC, Bright TJ, Wang SA: The genetic association database. Nat Genet 2004, 36:431-432. http://geneticassociationdb.nih.gov/.

45. Kent WJ, Sugnet CW, Furey TS, Roskin KM, Pringle TH, Zahler AM, Haussler D: The human genome browser at UCSC. Genome Res 2002, 12:996-1006. http://genome.ucsc.edu/.

46. Chelala C, Khan A, Lemoine NR: SNPnexus: a web database for functional annotation of newly discovered and public domain single nucleotide polymorphisms. Bioinformatics 2009, 25:655-661. http://snp-nexus.org/.

47. Bylund M, Andersson E, Novitch BG, Muhr J: Vertebrate neurogenesis is counteracted by Sox1-3 activity. Nat Neurosci 2003, 6:1162-1168.

48. Dominguez MH, Ayoub AE, Rakic P: POU-III Transcription factors (Brn1, Brn2, and Oct6) influence neurogenesis, molecular identity, and migratory destination of upper-layer cells of the cerebral cortex. Cereb Cortex 2013, 23:2632-2643.

doi:10.1186/2040-2392-5-48

Cite this article as: Di Napoli et al:: Genetic variation in the oxytocin receptor (OXTR) gene is associated with Asperger Syndrome. Molecular Autism 2014 5:48.

\section{Submit your next manuscript to BioMed Central and take full advantage of:}

- Convenient online submission

- Thorough peer review

- No space constraints or color figure charges

- Immediate publication on acceptance

- Inclusion in PubMed, CAS, Scopus and Google Scholar

- Research which is freely available for redistribution

Submit your manuscript at www.biomedcentral.com/submit
C) Biomed Central 